\title{
SYSTEMIC LUPUS ERYTHEMATOSUS PRESENTING AS HYPOKALEMIC
} PERIODIC PARALYSIS SECONDARY TO DISTAL RENAL TUBULAR ACIDOSIS

\author{
Ranjeet Kaur ${ }^{1}$, Gurinder Mohan²
}

\section{HOW TO CITE THIS ARTICLE:}

Ranjeet Kaur, Gurinder Mohan. "Systemic Lupus Erythematosus Presenting as Hypokalemic Periodic Paralysis Secondary to Distal Renal Tubular Acidosis". Journal of Evolution of Medical and Dental Sciences 2014; Vol. 3, Issue 19, May 12; Page: 5108-5111, DOI: 10.14260/jemds/2014/2561

ABSTRACT: Systemic lupus erythematosus, referred to as SLE or lupus, is sometimes called the "great imitator." Why? Because of its wide range of symptoms, people often confuse lupus with other health problems. We report the case of a 22-year-old woman who presented with a flaccid paralysis of limbs due to severe hypokalemia as a consequence of distal renal tubular acidosis (dRTA). A search for the cause of dRTA revealed latent Systemic Lupus Erythematosus (SLE). SLE presenting as dRTA is uncommon.

KEYWORDS: SLE -Systemic Lupus Erythematosus, dRTA - distal Renal Tubular Acidosis, AG- Anion Gap, TTKG- Transtubular Potassium Gradient.

INTRODUCTION: Renal tubular acidosis (RTA) is a group of disorders observed in patients with normal anion gap metabolic acidosis. There are three major forms of RTA: A proximal (type II) RTA and two types of distal RTAs (type I and type IV). Proximal (type II) RTA originates from the inability to reabsorb bicarbonate normally in the proximal tubule. Type I RTA is associated with inability to excrete the daily acid load and mostly present with hypokalemia. The most prominent abnormality in type IV RTA is hyperkalemia caused by hypoaldosteronism. Important causes of type 1 RTA include autoimmune diseases like Sjogren's syndrome, Rheumatoid arthritis, SLE, Polyarteritis nodosa, Thyroiditis, Primary biliary cirrhosis, Cryoglobulinemia. In our case, we are discussing type 1 RTA due to underlying SLE.

CASE REPORT: A 22-year-old woman presented in emergency ward in May 2010 with history of progressive weakness of both upper and lower limbs of 1 day duration. It was not related to exercise or meals, not associated with loss of consciousness, not associated with any trauma.

There was no respiratory distress or dysphagia. She had history of two to three episodes of vomiting for last 5 days which were non-projectile, non-blood stained, and non-foul smelling. There was no history of photosensitivity, rash, oral ulcer, arthralgia or arthritis, fever, dyspnea, genital ulcerations, abortions, oliguria, nocturia or pedal edema.

There is similar past history of hospitalization for quadriparesis one year back in January 2009, but no work was done to find the cause, as hypokalemia was attributed to vomiting associated at that time. Patient responded to I.V. treatment and discharged in stable condition. There is no relevant drug history. There was no significant family history.

Clinical examination was unremarkable except for decreased tone and power with sluggish deep tendon reflexes in both upper and lower limbs with no sensory deficit and a flexor plantar response.

Investigations revealed hemoglobin of $14.2 \mathrm{~g} / \mathrm{dl}$ with total white cell count of 19,000 and differential leukocyte count of neutrophils $87 \%$, lymphocytes $10 \%$, monocyte $1 \%$ and eosinophils of 
$2 \%$, platelet count was normal and with an erythrocyte sedimentation rate (ESR) of $40 \mathrm{~mm}$ in the first hour. Urine routine examination showed 3+ proteinuria, with 8-10 pus cells with many RBC, but urine culture revealed no growth.

Electrolyte Examination: $\left(\mathrm{Na}^{+}\right)$: $140 \mathrm{mmol} / \mathrm{L}$; potassium $\left(\mathrm{K}^{+}\right): 1.5 \mathrm{mmol} / \mathrm{L}$; chloride (Cl-): 123 mmol/L; calcium $\left(\mathrm{Ca}^{+2}\right): 8.9 \mathrm{mg} / \mathrm{dL}$; magnesium $\left(\mathrm{Mg}^{+2}\right): 2.3 \mathrm{mg} / \mathrm{dL}$; albumin: $3.0 \mathrm{gm} / \mathrm{dL}$, blood urea: $39 \mathrm{mg} / \mathrm{dL}$, serum creatinine: $1 \mathrm{mg} / \mathrm{dL}$ and random blood sugar $70 \mathrm{mg} / \mathrm{dL}$. Free T3, T4 and TSH were within normal limits.

Arterial blood gas showed a pH of 7.30; P02: $104 \mathrm{mmHg}$; PCO2: $20.5 \mathrm{mmHg}$ and bicarbonate level: $10.9 \mathrm{mmol} / \mathrm{L}$. The calculated anion gap A.G. was normal i.e. $\left\{\left(\mathrm{Na}^{+}+\mathrm{K}^{+}\right)-\left(\mathrm{Cl}^{-}+\mathrm{HCO}^{-}\right)\right\}$was $7.6 \mathrm{mmol} / \mathrm{L}$.

Urine Examination: Urinalysis showed a $\mathrm{pH}$ of 7.5, Urine potassium [K+] u: $18.9 \mathrm{mEq} / \mathrm{l}$ (Vol: 2.17L/day), Urine sodium [ $\left.\mathrm{Na}^{+}\right] \mathrm{u}: 97 \mathrm{mmol} / \mathrm{L}$, Urine chloride [Cl-] u: $112.2 \mathrm{mmol} / \mathrm{L}$. Trans tubular potassium gradient

$$
\left[\frac{\text { urine } k}{\text { plasma } k} / \frac{\text { urine osmo }}{\text { plasma osmo }}\right]
$$

i.e. TTKG is 5.

The calculated urinary anion gap $\left\{\right.$ urine $\left.\left(\mathrm{Na}^{+}+\mathrm{K}^{+}\right)-(\mathrm{Cl}-)\right\}$ was positive i.e. 3.7. Urine protein was 2 gram in $24 \mathrm{hrs}$. calculated after correction of pus cells. Serological tests revealed highly positive antinuclear antibodies (ANA) and anti dsDNA. Chest X Ray was normal and ultrasound of abdomen and pelvis showed small left renal calculus with GB sludge. Kidney biopsy was advised. A diagnosis of hypokalemic paralysis due to distal renal tubular acidosis most probably as a result of SLE with nephrocalcinosis and cystits was made.

TREATMENT: Patient started on i.v. antibiotics in the form of ceftriaxone 1gram i.v. bd, i.v potassium was started before correcting acidosis in the form of KCL at the rate of 10 meq over one hour continuous drip through central line. Patient responded to i/v treatment and results were following:-

Serum K- $2.5 \mathrm{mmol} / \mathrm{l}$ on first day (evening)

Serum K- $3.9 \mathrm{mmol} / \mathrm{l}$ on second day (morning)

Serum K-4.4 mmol/l on day second day (evening)

Then patient was started on potassium bicarbonate syrup 2 tsf t.d.s which could correct both hypokalemia and acidosis.

DISCUSSION: The renal acid-base homeostasis may be broadly divided into two processes: (1) reabsorption of filtered $\mathrm{HCO}_{3}{ }^{-}$, which occurs fundamentally in the proximal convoluted tubule; and (2) excretion of fixed acids through the titration of urinary buffers and the excretion of ammonium, which takes place primarily in the distal nephron. The characteristic feature of classic RTAs is inability to acidify the urine maximally (to less than $\mathrm{Ph} 5.3$ ) in the face of systemic acidosis. ${ }^{1}$

Acute motor weakness of limbs is the presenting symptom. Hypokalemic paralysis is primarily the result of either hypokalemic periodic paralysis (HPP) caused by an enhanced shift of Potassium $\left(\mathrm{K}^{+}\right)$into cells or non - HPP resulting from excessive urinary or gastrointestinal $\mathrm{K}+$ loss. In the presence of hypokalemia, urine potassium $<15 \mathrm{mmol} /$ day suggests extra renal loss, whereas $\left[\mathrm{K}^{+}\right]$ 
$\mathrm{u}>15 \mathrm{mmol} /$ day suggests renal loss as was the case in our patient. The urine anion gap (UAG) represents an indirect index of urinary $\mathrm{NH} 4+$ excretion in patients with hyperchloremic metabolic acidosis $^{2}$. UAG is defined by the equation: $\mathrm{UAG}=[\mathrm{Na}+] \mathrm{u}+[\mathrm{K}+] \mathrm{u}-[\mathrm{Cl}-] \mathrm{u}$ where $[\mathrm{Na}+] \mathrm{u}=$ urine sodium concentration, $[\mathrm{K}+] \mathrm{u}=$ urine potassium concentration and $[\mathrm{Cl}-] \mathrm{u}=$ urine chloride concentration (all units $\mathrm{mmol} / \mathrm{L}$ ). ${ }^{3}$

In the differential diagnosis of hyperchloremic metabolic acidosis, in the presence of systemic acidosis, a negative UAG indicates enhanced ammoniagenesis [as in proximal RTA (pRTA)] and a positive UAG suggests altered distal urinary acidification (as in distal RTA). ${ }^{3}$ Distal RTA is a clinical syndrome consisting of hypokalemia, hyperchloremic metabolic acidosis, inability to lower urine $\mathrm{pH}$ below 5 during acidemia, nephrocalcinosis and nephrolithiasis. ${ }^{4}$

It is very much evident that our patient had distal RTA (Type 1 RTA) with evidence of nephrocalcinosis/ lithiasis. The primary abnormality is a failure to lower urine $\mathrm{pH}$ in the presence of systemic acidosis because of impaired distal tubular $\mathrm{H}+$ secretion. Impaired $\mathrm{NH} 4+$ excretion is secondary to decreased trapping of NH3 in the collecting duct, because of the $\mathrm{H}+$ secretion defect. The molecular basis may include defects in the luminal membrane $\mathrm{H}+$ - ATPase or $\mathrm{H}+$ / K+ - ATPase. ${ }^{3}$

Our patient had a flaccid paresis due to severe hypokalemia as a consequence of dRTA due to latent SLE. The term latent or incomplete SLE is used when all the American College of Rheumatology (ACR) criteria for the diagnosis of SLE are not met, but there is a probability of the disease manifesting fully later on. Patients with disease symptoms related to one organ system only, together with the presence of positive ANA, can be said to have incomplete SLE. 5

dRTA occurring in immunological disorders such as Sjogren's syndrome and SLE is thought to result from an interstitial nephritis which various investigators have ascribed to mononuclear cell infiltration, deposition of antigen - antibody complexes along tubular basement membranes and formation of antibodies directed against the tubular basement membrane ${ }^{6}$. Study done by Ter Meulen C.G et al. revealed cases in which features of dRTA preceded other manifestations of SLE by 46 years. ${ }^{4}$

Long-term correction of the hypokalemia is important to overcome the neuromuscular impairment and to prevent further deterioration of kidney function. It has been suggested that hypokalemia stimulates interstitial deposition of complement (C3, C5ba), which is conducive to the aggravation of renal interstitial damage. ${ }^{7}$ dRTA has been described in membranous nephropathy \& SLE nephritis with proteinuria ${ }^{8,9}$. In SLE nephropathy, deposits of immune complexes may be seen in tubular basement membranes. Similarly in anti-GBM disease, antibodies are reactive against tubular basement membrane. Osteopontin, a cell attachment glycoprotein may have some role in tubulointerstitial injury in glomerulonephritis by monocyte/ macrophage accumulation. ${ }^{10}$

HPP has been described occasionally in pRTA. ${ }^{11,12}$ It is common in dRTA. It is characterized by recurrent episodes of hypokalemia and acute systemic weakness.

We suggest that patients with hypokalemic paralysis be evaluated to rule out dRTA and further propose that adults with documented dRTA be closely evaluated for symptoms, signs and laboratory evidence of autoimmune disorders. In conclusion, distal renal tubular acidosis can be the first manifestation of SLE, preceding other symptoms by a few years. 


\section{BIBLIOGRAPHY:-}

1. DuBose TD, McDonald GA. Renal tubular acidosis. In: Du Bose TD, Hamm LL, eds. Acid-Base and Electrolyte Disorders: A Companion to Brenner and Rector's The Kidney. Philadelphia: WB Saunders, 2002: 189-206.

2. Juan Rodriguez Soriano. Renal Tubular Acidosis: The Clinical Entity. J Am Soc Nephrol 2002; 13:2160-2170.

3. Penny MD, Oleesky DA. Renal tubular acidosis. Ann Clin Biochem 1999; 36: 408 -422.

4. Ter Meulen C.G, Pieters GFFM, Huysmans FTM. Flaccid paresis due to distal renal tubular acidosis preceding systemic lupus erythematosus. Neth J Med 2002; 60: 29-32.

5. Swaak AJG, van de Brink H, Smeenk RJT et al. Incomplete lupus erythematosus: results of a multicentre study under the supervision of the EULAR standing committee on International clinical studies including therapeutic trials (ESCISIT). Rheumatology 2001; 40:89-94.

6. Caruana RJ, Barish CF, Buckalew VM Jr. Complete distal renal tubular acidosis in systemic lupus: Clinical and laboratory findings. Am J Kid Dis 1985; 6: 59-63.

7. Nakhoul F, Plavnic Y, Lichtig H, Better OS. Hypokalemic flaccid paralysis as the presenting symptom of autoimmune interstitial nephropathy. Isr J Med Sci 1993; 29: 300-303.

8. Padmanabhan S, Lakshmi AY, Siva Kumar V. Membranous nephropathy and distal RTA with medullary nephrocalcinosis. Indian J. Nephrol 2005; 15: 33-34.

9. Li SL, Lion LB, Fang JT, Tsai WP. Symptomatic renal tubular acidosis in a patient with SLE: an analysis of 6 cases with new association of Type 4 RTA. Rheumatology 2005; 44: 1176-1180.

10. Pichler R, Gracheilli CM, Lombardi D et al. Tubulo interstitial disease in glomerulonephritis. Potential role of osteopontin (aropontin). Am J Pathol 1994; 144: 915-926.

11. Rao N, John M, Thomas $\mathrm{N}$ et al. Aetiological, clinical and metabolic profile of HPP in adults: a single centre experience. Nat Med J India 2006; 19: 246-249.

12. Chang YC, Huang CC, Chiou YY, Nu CY. RTA complicated with HPP. Pediatr Neurol 1995; 13: 5254.

\section{AUTHORS:}

1. Ranjeet Kaur

2. Gurinder Mohan

\section{PARTICULARS OF CONTRIBUTORS:}

1. Assistant Professor, Department of General Medicine, Sri Guru Ram Das Institute of Medical Sciences and Research, Amritsar.

2. Professor, Department of General Medicine, Sri Guru Ram Das Institute of Medical Sciences and Research, Amritsar.

\section{NAME ADDRESS EMAIL ID OF THE} CORRESPONDING AUTHOR:

Dr. Ranjeet Kaur,

Simran Hospital,

Opposite Rayon and Silk Mills, Opposite Old Octroi GT Road,

Chhesarta, Amritsar.

Email: manishksharma27@gmail.com

Date of Submission: $11 / 04 / 2014$.

Date of Peer Review: 12/04/2014.

Date of Acceptance: 23/04/2014.

Date of Publishing: 07/05/2014. 